\title{
Uma análise da relação entre os conceitos Enade e IDD*
}

HÉLIO RADKE BITTENCOURT

PUCRS

LORÍ VIALI

PUCRS e UFRGS

ALAM DE OLIVEIRA CASARTELLI

PUCRS

ALZIRO CESAR DE M. RODRIGUES

PUCRS

\section{RESUMO}

A criação do Indicador de Diferença de Desempenho (IDD) pode ser considerada a principal inovação do Exame Nacional de Desempenho dos Estudantes (ENADE) em relaçáo ao antecessor Exame Nacional de Cursos, mais conhecido como "Provão". O IDD visa a responder a críticas que apontavam para o favorecimento de instituições públicas na obtenção de conceitos mais elevados, influenciados pelo nível de entrada dos alunos, supostamente mais elevado em razão das dificuldades de ingresso. Este artigo propóe-se a examinar especificamente os dois conceitos derivados do ENADE - o próprio conceito Enade e o IDD - e a relação entre eles. Para embasar a discussão, uma análise estatística dos resultados encontrados na avaliação trienal 2004-2006 é apresentada.

Palavras-chave: IDD, ENADE, avaliação do ensino superior, ensino superior.

"Neste texto será feita a seguinte distinção: ENADE em letras maiúsculas é uma referência ao Exame Nacional de Desempenho de Estudantes. "Enade", apenas com a inicial maiúscula, se refere ao conceito Enade, um dos indicadores derivados do Exame Nacional. 


\section{RESUMEN}

La creación del Indicador de Diferencia de Desempeño (IDD) puede ser considerada la principal innovación del Examen Nacional de Desempeño de los Estudiantes (ENADE) en relación al anterior Examen Nacional de Cursos, más conocido como "Provão". El IDD busca responder a críticas que señalaban el beneficio de instituciones públicas en la obtención de conceptos más elevados, influenciados por el nivel de ingreso de los alumnos, supuestamente más elevado debido a las dificultades de dicho ingreso. Este artículo se propone examinar específicamente los dos conceptos derivados del ENADE - el propio concepto Enade y el IDD - y la relación entre ellos. Para dar soporte a la discusión, se presenta también un análisis estadístico de los resultados obtenidos en la evaluación trienal (2004-2006).

Palabras clave: IDD, ENADE, evaluación de la educación superior, educación superior.

\section{ABSTRACT}

The Gap Performance Index (IDD) could be considered the main innovation of the National Exam of Students' Performance (ENADE) related to the National Exam of Courses, known as "Provão". IDD aims to respond to criticisms which pointed to results that favored public institutions in obtaining higher evaluations, influenced by their students' entry level, supposedly higher because access conditions are more difficult. This paper specifically examines both concepts derived from ENADE - the ENADE concept itself and the IDD concept - focusing on their relationship. In order to support the discussion, a statistical analysis of the results from the years 2004-2006 is presented.

Keywords: IDD, ENADE, higher education evaluation, higher education. 


\section{INTRODUÇÃO}

Os diferentes procedimentos para avaliação de cursos e instituições de ensino superior (IES) no Brasil vêm apresentando uma evolução constante e consistente, como sugerem Dias, Horiguela e Marcuelli (2006) ao realizarem um balanço crítico sobre as políticas de avaliação da qualidade do ensino superior brasileiro.

O Exame Nacional de Cursos (Provão), realizado no período de 1996 a 2003 com estudantes formandos de graduaçáo, foi a primeira tentativa visando a avaliar o processo de ensino-aprendizagem de cursos de várias áreas. Na última ediçáo, realizada em 2003, participaram mais de 470 mil formandos de 6,5 mil cursos e 26 áreas. Em 2004, o Provão foi substituído pelo Exame Nacional de Desempenho dos Estudantes (ENADE).

Se, por um lado, o Provão avaliava todos os formandos de um conjunto de cursos universitários, o ENADE, por outro, é aplicado a uma amostra de concluintes e outra de ingressantes. Esta segunda forma de avaliaçáo foi criada para responder principalmente às críticas de universidades particulares que sustentavam que o Provão baseavase apenas no produto final, sem considerar o desempenho dos alunos ingressantes. $\mathrm{O}$ Provão avaliava, anualmente, estudantes de todos os cursos que ingressavam paulatinamente no rol de cursos avaliados, enquanto o ENADE dividiu um conjunto mais abrangente de cursos em três blocos, avaliando apenas um desses blocos a cada ano. Com essa abordagem, o ciclo de avaliaçáo se completa em três anos.

O ENADE é parte do Sistema Nacional de Avaliação da Educação Superior (Sinaes), tendo sido proposto em 2003 e formalmente instituído pela Lei n. 10.861, aprovada em 2004. O Sinaes também inclui uma auto-avaliação das instituiçóes, uma avaliação externa do corpo docente e da infra-estrutura e uma avaliação específica de cada curso de Graduaçáo, realizada por avaliadores selecionados pelo Ministério da Educação (MEC). Entretanto, ainda que o Sinaes seja um processo completo de avaliação, a maioria das IES e os meios de comunicação dão mais destaque ao conceito Enade e ao Indicador de Diferença de Desempenho (IDD), ambos baseados no desempenho dos alunos. Conforme enfatizam Ristoff e Giolo (2006), grande parte da sociedade, da imprensa e até mesmo os próprios alunos pensam que o Sinaes se resume ao ENADE.

Uma extensa lista de textos científicos tem discutido e comparado os diferentes procedimentos de avaliação do ensino superior adotados no Brasil. Vianna (2003) analisa propostas de avaliaçóes em larga escala anteriores ao Sinaes. Verhine, Dantas e Soares (2006) apontam para grandes similaridades entre o atual Enade e o seu antecessor Provão, ainda que admitam avanços, como o fazem Dias, Horiguela e Mar- 
cuelli (2006) e Polidori, Marinho-Araújo e Barreyro (2006). Gouveia et al. (2005) ressaltam singularidades e contradiçóes entre os sistemas de avaliação utilizados nas últimas duas décadas no Brasil. Tendo por objetivo enriquecer o debate e a discussão sobre o tema, este artigo propóe-se a discutir especificamente os dois indicadores do ENADE - o próprio conceito Enade e o IDD - e a relação entre eles. O interesse por esse tema surgiu não só por sua importância no âmbito das IES brasileiras, mas também como fruto de questionamentos formulados por professores da Pontifícia Universidade Católica do Rio Grande do Sul (PUCRS), aos autores deste artigo, em palestras e reunióes proferidas sobre o Enade 2006.

Nas seções subseqüentes são apresentados, de forma resumida, a descrição da metodologia utilizada para definição dos conceitos Enade e IDD; uma discussão sobre o coeficiente utilizado para medir a concordância entre os dois conceitos; os resultados obtidos no Enade 2006 e as consideraçóes finais.

\section{A MOTIVAÇÃO PARA A CRIAÇÃO DO IDD}

Uma queixa recorrente de IES privadas, quanto aos procedimentos de avaliação do Ensino Superior no Brasil, se refere à igualdade de tratamento em relação às instituiçôes públicas, especialmente as federais, onde a dificuldade de ingresso tenderia a selecionar naturalmente alunos mais bem preparados. A criação do IDD é motivada como resposta a tais críticas, podendo ser considerada a maior inovação do atual sistema em relação ao antecessor Provão.

No IDD os candidatos são avaliados em relação ao desempenho médio esperado para estudantes em condições supostamente semelhantes. O índice IDD representa a diferença entre o desempenho médio dos concluintes relacionado com os resultados médios de outras IES, cujos ingressantes tenham perfil semelhante. Em tese, esse parece ser um indicador mais justo do que o conceito Enade, pois leva em conta o perfil dos candidatos, promovendo, assim, uma concorrência entre indivíduos supostamente nivelados quanto às condiçóes de entrada (Brasil, 2006).

O conceito Enade, por sua vez, é derivado de uma espécie de competição entre todos os cursos avaliados, não importando a bagagem anterior dos candidatos. Assim, parece evidente que os cursos mais concorridos, geralmente das universidades públicas, tenham uma vantagem competitiva bastante acentuada por já terem efetuado uma seleção rigorosa no ingresso de candidatos. O IDD buscou levar esse fator em consideração, atribuindo-se uma espécie de handicap em que os concorrentes seriam nivelados pelas condiçóes de ingresso e, dessa forma, propiciando que a disputa se dê em condiçóes mais equilibradas. 


\section{ASPECTOS METODOLÓGICOS}

Os dados analisados neste texto foram extraídos da base do Instituto Nacional de Estudos e Pesquisas Educacionais Anísio Teixeira (Inep), referindo-se ao triênio 2004-2006. A consulta à base de dados foi realizada em abril de 2008. Os resultados apresentados são passíveis de pequena variação se comparados aos relatórios do próprio Inep, em razão de eventuais alteraçôes de conceitos.

Em três ediçóes já realizadas, o ENADE avaliou um total de 13.397 cursos de aproximadamente 2.000 IES. Em 2004, os cursos avaliados foram das áreas de: Agronomia, Educação Física, Enfermagem, Farmácia, Fisioterapia, Fonoaudiologia, Medicina, Medicina Veterinária, Nutrição, Odontologia, Serviço Social, Terapia Ocupacional e Zootecnia. Em 2005, avaliou-se Arquitetura e Urbanismo, Biologia, Ciências da Computação, Ciências Sociais, Engenharias, Filosofia, Física, Geografia, História, Letras, Matemática, Pedagogia e Química. Por fim, em 2006, os cursos avaliados foram: Administração, Arquivologia, Biblioteconomia, Biomedicina, Ciências Contábeis, Ciências Econômicas, Comunicação Social, Design, Direito, Música, Normal Superior, Psicologia, Secretariado Executivo, Teatro e Turismo.

Com o propósito de investigar a relação entre os conceitos Enade e IDD foram utilizadas técnicas estatísticas bivariadas (tabelas de contingência e o coeficiente Kappa) e técnicas descritivas convencionais (média aritmética, desvio padrão, gráficos etc.). Optou-se, também, pela inclusão de um texto explicativo sobre o coeficiente Kappa de Cohen ${ }^{1}$ em virtude de sua importância para este trabalho e pelo fato de o mesmo náo ser considerado uma medida estatística padráo na área da educação.

\subsection{O Coeficiente de Concordância Kappa}

Proposto inicialmente por Cohen (1960), o coeficiente Kappa ( $k$ ) procura mensurar a intensidade e a qualidade da concordância entre duas classificaçóes (Viali; Bittencourt, 2007), e vem sendo utilizado para quantificar a concordância entre juízes no campo da Psicometria. Esse coeficiente decompóe a concordância em duas partes: uma relacionada ao acerto casual e outra denominada "concordância confiável”. Essa decomposição mostra-se necessária, porque mesmo classificaçóes absolutamente independentes podem apresentar concordâncias casuais (Everitt, 1992). Considere o exemplo apresentado na tabela 1 , no qual duas moedas honestas foram lançadas simultaneamente por 12 vezes. $\mathrm{O}$ resultado esperado consiste de seis caras

${ }^{1}$ Jacob Cohen (1923-1998). Estatístico e psicólogo americano. 
(K) e seis coroas (C) para cada moeda, com três ocorrências de cada combinação (KK, KC, CK, CC).

Tabela 1 - Seqüência de resultados em 12 lançamentos de um par de moedas

\begin{tabular}{c|cccccccccccc}
\hline & $1^{\circ}$ & $2^{\circ}$ & $3^{\circ}$ & $4^{\circ}$ & $5^{\circ}$ & $6^{\circ}$ & $7^{\circ}$ & $8^{\circ}$ & $9^{\circ}$ & $1^{\circ}$ & $1^{\circ}$ & $1^{\circ}$ \\
\hline Moeda A & C & K & C & C & C & K & K & C & C & K & C & K \\
\hline Moeda B & C & K & C & C & K & K & C & K & C & K & K & C \\
\hline
\end{tabular}

Legenda: cara $(\mathrm{K})$, coroa $(\mathrm{C})$

Os resultados possíveis dos lançamentos das duas moedas estão organizados na tabela 2 e mostram que, como era de se esperar, ficaram próximos de três ocorrências por célula.

Tabela 2 - Cruzamento entre os resultados de 12 lançamentos de um par de moedas

\begin{tabular}{lccc}
\hline \multirow{2}{*}{ Moeda A } & \multicolumn{2}{c}{ Moeda B } & \multirow{2}{*}{ Total } \\
\cline { 2 - 3 } & Coroa (C) & Cara (K) & \\
\hline Coroa (C) & 4 & 3 & 7 \\
Cara (K) & 2 & 3 & 5 \\
\hline Total & 6 & 6 & 12 \\
\hline
\end{tabular}

Os resultados da tabela 2 mostram um porcentual de concordância observado (Po) de 7/12, formado pela soma dos elementos da diagonal (4+3). O porcentual de concordância esperado $(P e)$ é de 6/12. O coeficiente Kappa estabelece uma comparação entre $P o$ e $P e$ por meio da seguinte relação

$$
k=\frac{P o-P e}{1-P e},
$$

de forma que o coeficiente resultará máximo $(k=1)$ apenas em caso de concordância completa $(P o=1)$. Neste exemplo tem-se $k=[(7 / 12)-(6 / 12)] /[1-(6 / 12)]=1 / 6$ $\cong 0,167$, revelando uma concordância baixa, conseqüência da independência entre os dois lançamentos. $\mathrm{Na}$ interpretação do coeficiente Kappa, valores de referência têm sido amplamente utilizados, mesmo que apresentem um caráter subjetivo. A tabela 3 apresenta uma classificação que tem sido amplamente encontrada na literatura especializada. 
Tabela 3 - Valores de referência para o coeficiente Kappa $(k)$

\begin{tabular}{cc}
\hline Valores & Concordância \\
\hline$<0$ & Sem concordância \\
$0,00-0,19$ & Pobre \\
$0,20-0,39$ & Regular \\
$0,40-0,59$ & Moderada \\
$0,60-0,79$ & Substancial \\
$0,80-1,00$ & Quase perfeita \\
\hline
\end{tabular}

Fonte: Landis e Koch, 1977.

\section{O FUNCIONAMENTO DO ENADE}

A prova do ENADE é dividida em duas partes. A primeira de Formação Geral (FG) consiste de 10 questóes, sendo duas discursivas e oito objetivas. A segunda de Componente Específico (CE) é composta por 30 questóes, entre discursivas e objetivas. A prova tem duração de quatro horas e é aplicada a amostras de ingressantes de cursos de Graduação, com 7 a 22\% da carga horária do curso concluída; e de concluintes com pelo menos $80 \%$ da carga horária do curso concluída.

O quadro 1 apresenta um resumo dos procedimentos para determinação do conceito Enade de um curso.

\section{Quadro 1 - Procedimentos para atribuição do conceito Enade*}

1. Calcula-se a média e o desvio-padrão de todos os alunos da instituição que fizeram a prova tanto ingressantes (I) como concluintes (C), tanto na formação geral (FG) como no componente específico (CE).

2. Calcula-se o afastamento padronizado (AP) para os seguintes grupos: $C E$ dos concluintes (CEC) e dos ingressantes ( $\left.C E^{\prime}\right)$ e $F G$ dos ingressantes + concluintes $\left(F G^{1+C}\right)$. O AP é um escore que normalmente varia entre -3 e +3 . Ele indica quantos desvios-padrão, acima ou abaixo da média, está o curso em relação aos demais concluintes da área.

3. Transforma-se o AP que geralmente varia de -3 a +3 para uma nota no intervalo de 0 a 5 . Esta nova escala é efetivamente usada para a atribuição de conceitos. Os cursos que estão abaixo de -3 e acima de +3 são considerados atípicos e não são considerados para a mudança de escala. Aqueles que estão abaixo de -3 recebem grau 0 e os que estão acima recebem grau 5.

4. Calcula-se a média geral (MG) do curso levando-se em conta as três notas - $\mathrm{CE}^{\mathrm{C}}, \mathrm{CE}^{\prime}, \mathrm{FG}^{\mathrm{I}+\mathrm{C}}$ com as ponderações de $60 \%, 15 \%$ e $25 \%$, respectivamente.

5. Define-se o conceito de acordo com a MG:

$\begin{array}{lccccc}\text { MG } & 0,0 \text { a } 0,9 & 1,0 \text { a } 1,9 & 2,0 \text { a } 2,9 & 3,0 \text { a } 3,9 & 4,0 \text { a } 5,0 \\ \text { Conceito } & 1 & 2 & 3 & 4 & 5\end{array}$

* Elaborado pelos autores. 
Conforme explicitado no item 3 do quadro acima, além do conceito Enade, existe a atribuiçáo do Indicador de Diferença de Desempenho (IDD), motivado pelo fato de que o perfil dos ingressantes varia entre os cursos e entre as IES, fazendo com que as notas dos concluintes tendam a refletir essas desigualdades. Conseqüentemente, é possível que diferenças entre os egressos não sejam explicadas apenas pelo que o respectivo curso agregou, mas, também, pelas diferenças pré-existentes (Brasil, 2006). Visando a eliminar a influência do nível de entrada sobre os resultados dos concluintes, é calculada a nota esperada do curso, por meio de análise de regressão linear, levando-se em conta três variáveis: 1) desempenho médio dos ingressantes; 2) proporção de estudantes cujos pais têm ensino superior; 3) razão entre o número de concluintes e ingressantes.

Além da influência dessas três variáveis, o modelo linear adiciona uma constante que representa o incremento médio dos concluintes em relação aos ingressantes no curso. Assim, um curso no qual os ingressantes apresentaram baixo desempenho nas provas e cujos pais não tenham escolaridade superior pode obter o conceito IDD máximo (5) mesmo que seus concluintes tenham um desempenho inferior aos de uma instituição onde o nível de entrada dos ingressantes é alto e os pais têm alto nível de escolaridade.

A figura 1, abaixo, ilustra o procedimento de atribuição dos conceitos IDD que, assim como o conceito Enade, apresenta cinco níveis. A figura 1 é uma representação bidimensional de um fenômeno multidimensional visto que, na verdade, há seis

Figura 1 - Atribuição dos conceitos IDD de acordo com o desempenho geral dos ingressantes e concluintes*

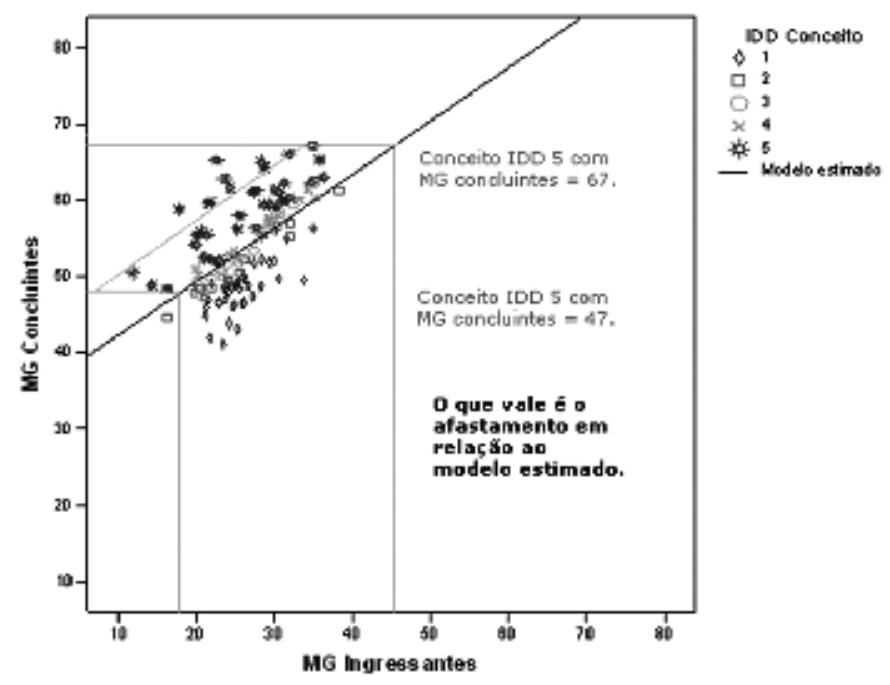

${ }^{*}$ A reta simboliza o desempenho esperado. 
variáveis envolvidas no processo de determinação do IDD: a) FG dos ingressantes; b) FG dos concluintes; c) CE dos ingressantes; d) CE dos concluintes; e) proporção de estudantes cujos pais têm ensino superior; f) razão entre o número de concluintes e ingressantes. Na figura 1, cada ponto representa uma IES.

Percebe-se que uma instituição pode obter o conceito IDD 5 com uma média dos concluintes em torno de 50; média igual a de cursos com conceito IDD 1. Isso ocorre porque a atribuiçáo do IDD se dá em funçáo da distância entre o ponto e a reta (modelo estimado). Quanto mais positiva é a distância entre o ponto e o modelo, maior é a agregação de valor em relação ao desempenho esperado. Pode-se dizer, portanto, que um ponto acima da reta representa um curso que superou as expectativas, considerando-se seu perfil.

\section{CONCEITOS ENADE E IDD - RESULTADOS EM ÂMBITO NACIONAL}

Os dados do último ENADE realizado foram divulgados em junho de 2007, tendo como base o ano de 2006. Com essa edição, o ciclo trienal de avaliação foi fechado, de forma que os três grupos de cursos superiores já foram avaliados. Está prevista para meados de 2008 a divulgação dos resultados do ENADE 2007, contemplando novamente os cursos avaliados em 2004. A distribuição dos conceitos Enade e IDD, em âmbito nacional para o triênio 2004-2006, é apresentada na tabela 4.

Tabela 4 - Conceitos Enade e IDD em âmbito nacional - 2004-2006

\begin{tabular}{|c|c|c|c|c|c|c|c|}
\hline & & \multicolumn{2}{|c|}{2004} & \multicolumn{2}{|c|}{2005} & \multicolumn{2}{|c|}{2006} \\
\hline \multirow{8}{*}{ ENADE } & Nível & $\begin{array}{l}N^{\circ} \text { de } \\
\text { cursos }\end{array}$ & $\%$ & $\begin{array}{l}\mathrm{N}^{\circ} \mathrm{de} \\
\text { cursos }\end{array}$ & $\%$ & $\begin{array}{l}N^{\circ} \text { de } \\
\text { cursos }\end{array}$ & $\%$ \\
\hline & 1 & 33 & 2,3 & 116 & 3,0 & 93 & 2,4 \\
\hline & 2 & 115 & 8,1 & 653 & 17,1 & 993 & 25,5 \\
\hline & 3 & 565 & 39,6 & 2024 & 52,9 & 1913 & 49,1 \\
\hline & 4 & 564 & 39,5 & 849 & 22,2 & 697 & 17,9 \\
\hline & 5 & 150 & 10,5 & 181 & 4,7 & 198 & 5,1 \\
\hline & Total & 1427 & 100,0 & 3823 & 100,0 & 3894 & 100,0 \\
\hline & $\begin{array}{c}\text { Sem } \\
\text { conceito }\end{array}$ & 757 & & 1688 & & 1808 & \\
\hline \multirow{7}{*}{ IDD } & 1 & 107 & 8,2 & 206 & 6,3 & 171 & 4,8 \\
\hline & 2 & 321 & 24,7 & 891 & 27,2 & 846 & 23,8 \\
\hline & 3 & 490 & 37,6 & 1287 & 39,3 & 1436 & 40,4 \\
\hline & 4 & 288 & 22,1 & 680 & 20,8 & 877 & 24,6 \\
\hline & 5 & 96 & 7,4 & 213 & 6,5 & 228 & 6,4 \\
\hline & Total & 1302 & 100,0 & 3277 & 100,0 & 3558 & 100,0 \\
\hline & $\begin{array}{c}\text { Sem } \\
\text { conceito }\end{array}$ & 882 & & 2234 & & 2144 & \\
\hline
\end{tabular}

Fonte: Brasil, 2006. 
De acordo com o Ministério da Educação (MEC), os conceitos 1 e 2 são considerados baixos, o conceito 3 é considerado regular e os níveis 4 e 5 são classificados como altos. Tanto o IDD como o conceito Enade apresentam uma distribuição concentrada no nível 3 (regular). Tal comportamento não surpreende, porque a atribuição dos conceitos ocorre em função do afastamento padronizado. Além disso, resultados de concursos públicos e vestibulares, por exemplo, tendem a apresentar uma distribuição aproximadamente normal ou gaussiana (Viali; Bittencourt, 2007). Mesmo após a categorização, é possível perceber a existência de um modelo subjacente que se assemelha à curva de Gauss, conforme representado na figura 2 .

Figura 2 - Distribuição nacional dos conceitos Enade e IDD - 2004-2006
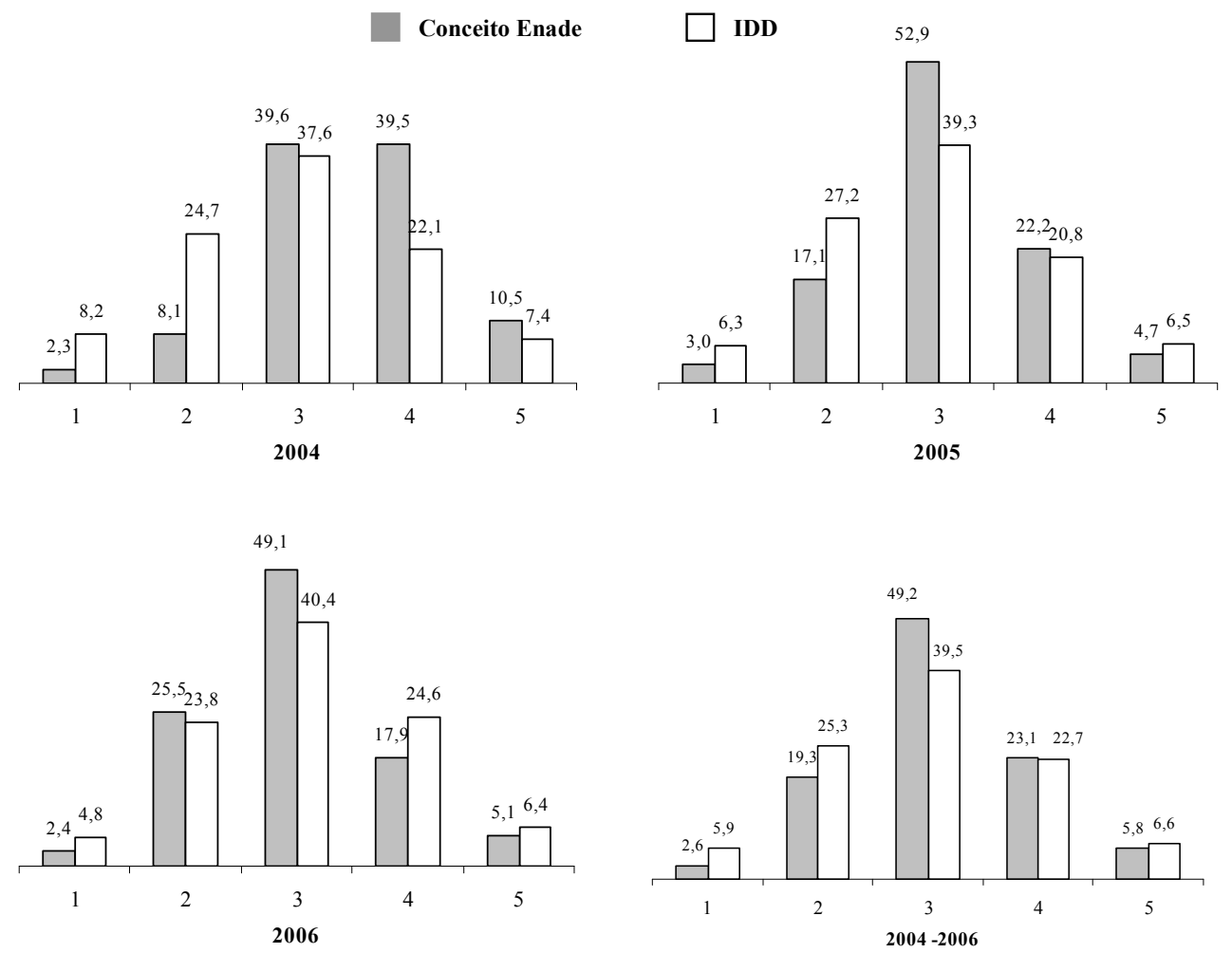

A tabela 5 mostra o cruzamento entre os conceitos Enade e IDD, revelando um coeficiente de concordância $k=0,14$, considerado pobre de acordo com os valores de referência de Landis e Koch (1977). 
Tabela 5 - Conceitos Enade e IDD em âmbito nacional - 2004-2006

\begin{tabular}{|c|c|c|c|c|c|c|}
\hline \multirow{2}{*}{ Enade } & \multicolumn{5}{|c|}{ IDD } & \multirow{2}{*}{ Total } \\
\hline & 1 & 2 & 3 & 4 & 5 & \\
\hline \multirow[t]{2}{*}{1} & 33 & 46 & 33 & 16 & 2 & 130 \\
\hline & $0,4 \%$ & $0,6 \%$ & $0,4 \%$ & $0,2 \%$ & $0,0 \%$ & $1,6 \%$ \\
\hline \multirow[t]{2}{*}{2} & 210 & 655 & 545 & 120 & 16 & 1546 \\
\hline & $2,6 \%$ & $8,0 \%$ & $6,7 \%$ & $1,5 \%$ & $0,2 \%$ & $19,0 \%$ \\
\hline \multirow[t]{2}{*}{3} & 186 & 1065 & 1809 & 857 & 163 & 4080 \\
\hline & $2,3 \%$ & $13,1 \%$ & $22,2 \%$ & $10,5 \%$ & $2,0 \%$ & $50,1 \%$ \\
\hline \multirow[t]{2}{*}{4} & 54 & 264 & 690 & 658 & 238 & 1904 \\
\hline & $0,7 \%$ & $3,2 \%$ & $8,5 \%$ & $8,1 \%$ & $2,9 \%$ & $23,4 \%$ \\
\hline \multirow[t]{2}{*}{5} & 1 & 28 & 136 & 194 & 118 & 477 \\
\hline & $0,0 \%$ & $0,3 \%$ & $1,7 \%$ & $2,4 \%$ & $1,5 \%$ & $5,9 \%$ \\
\hline \multirow{2}{*}{ Total } & 484 & 2058 & 3213 & 1845 & 537 & 8137 \\
\hline & $5,9 \%$ & $25,3 \%$ & $39,5 \%$ & $22,7 \%$ & $6,6 \%$ & $100,0 \%$ \\
\hline
\end{tabular}

Observações: a) Kappa $=0,14$; b) $O$ total se refere apenas aos cursos que possuem os dois conceitos; c) Porcentual calculado sobre o total da tabela ( $\mathrm{N}=8137$ cursos).

Fonte: Brasil, 2006.

Os resultados apresentados na tabela 5 revelam, também, que apenas dois cursos apresentaram o antagonismo de um conceito Enade máximo associado a um IDD mínimo (ou vice-versa). Além disso, 40,2\% dos cursos apresentaram exatamente os mesmos conceitos Enade e IDD, o que sugere uma associaçáo direta entre eles. Para auxiliar na interpretação, os conceitos foram reclassificados de acordo com a nomenclatura sugerida pelo próprio MEC (1-2: baixo; 3: regular; 4-5: alto), possibilitando a construção da tabela 6 que, por ser mais resumida, tende a facilitar a interpretaçáo do leitor. Nessa tabela um curso que apresenta conceito Enade baixo tem apenas 9,2\% de probabilidade de apresentar um conceito IDD alto. Tal probabilidade sobe para 50,7\% em um curso com conceito Enade alto. Esse resultado sugere que há uma relação direta entre os conceitos.

Tendo por objetivo avaliar, de forma mais pontual, a associação entre os conceitos, esses mesmos indicadores foram calculados separadamente para os dez cursos mais freqüentes avaliados pelo ENADE. A tabela 7 mostra os resultados dos coeficientes Kappa e as probabilidades condicionais de um curso com Enade baixo apresentar um IDD alto.

Os resultados da tabela 7 revelam uma fraca associaçáo entre os conceitos Enade e IDD, em praticamente todas as áreas, o que é evidenciado por coeficientes Kappa baixos, 
Tabela 6 - Conceitos Enade e IDD em âmbito nacional, agrupados em três categorias - 2004-2006

\begin{tabular}{lcccc}
\hline \multirow{2}{*}{ Enade } & \multicolumn{3}{c}{ IDD } & \multirow{2}{*}{ Total } \\
\cline { 2 - 4 } & Baixo (1-2) & Regular (3) & Alto (4-5) & \\
\hline Baixo (1-2) & 944 & 578 & 154 & 1676 \\
Regular ( 3) & $56,3 \%$ & $34,5 \%$ & $9,2 \%$ & $100,0 \%$ \\
& 1251 & 1809 & 1020 & 4080 \\
Alto (4-5) & $30,7 \%$ & $44,3 \%$ & $25,0 \%$ & $100,0 \%$ \\
& 347 & 826 & 1208 & 2381 \\
\hline Total & $14,6 \%$ & $34,7 \%$ & $50,7 \%$ & $100,0 \%$ \\
\hline & 2542 & 3213 & 2382 & 8137 \\
& $31,2 \%$ & $39,5 \%$ & $29,3 \%$ & $100,0 \%$ \\
\hline
\end{tabular}

Observações: a) Kappa $=0,21$; b) Porcentual calculado sobre os totais das linhas.

Fonte: Brasil, 2006.

Tabela 7 - Coeficientes Kappa entre Enade e IDD para os 10 cursos mais freqüentes, separadamente para 5 e 3 níveis e probabilidades condicionais

\begin{tabular}{|c|c|c|c|c|c|}
\hline \multirow[b]{2}{*}{ Áreas } & \multirow[b]{2}{*}{$\begin{array}{c}\text { Kappa } \\
\text { (5 níveis) }\end{array}$} & \multirow[b]{2}{*}{$\begin{array}{c}\text { Kappa } \\
\text { (3 níveis) }\end{array}$} & \multicolumn{2}{|c|}{ Probabilidade de } & \multirow[b]{2}{*}{$\begin{array}{l}N^{\circ} \text { de curso } \\
\text { com os dois } \\
\text { conceitos }\end{array}$} \\
\hline & & & $\begin{array}{c}\text { Um curso } \\
\text { com Enade } \\
\text { baixo ter IDD } \\
\text { alto }\end{array}$ & $\begin{array}{c}\text { Um curso } \\
\text { com Enade } \\
\text { alto ter IDD } \\
\text { alto }\end{array}$ & \\
\hline Administração & 0,16 & 0,23 & $8,7 \%$ & $70,3 \%$ & 1072 \\
\hline Pedagogia & 0,27 & 0,34 & $5,7 \%$ & $65,2 \%$ & 597 \\
\hline Ciências Contábeis & 0,21 & 0,31 & $4,6 \%$ & $62,4 \%$ & 518 \\
\hline Direito & 0,13 & 0,20 & $8,4 \%$ & $52,2 \%$ & 497 \\
\hline Letras & 0,17 & 0,25 & $3,7 \%$ & $47,6 \%$ & 451 \\
\hline Biologia & 0,17 & 0,23 & $4,3 \%$ & $50,0 \%$ & 295 \\
\hline Matemática & 0,15 & 0,19 & $5,4 \%$ & $60,9 \%$ & 259 \\
\hline C. Computação (SI) & 0,16 & 0,24 & $13,5 \%$ & $67,9 \%$ & 214 \\
\hline Turismo & 0,23 & 0,32 & $7,4 \%$ & $67,5 \%$ & 183 \\
\hline Normal Superior & 0,22 & 0,29 & $14,3 \%$ & $82,2 \%$ & 152 \\
\hline
\end{tabular}

classificados como regulares ou pobres, de acordo com os valores de referência de Landis e Koch (1977). De qualquer forma, chama a atenção que todos os coeficientes são positivos, apesar de, matematicamente, haver a possibilidade de valores negativos. Tal resultado sugere uma relação direta entre os conceitos, ainda que de intensidade baixa.

Associando-se a tabela 7 à figura 3, percebe-se que a probabilidade de um curso com conceito 1 ou 2 no Enade obter um IDD alto fica abaixo de 10\% em nove das 
15 áreas investigadas. Admitindo-se total independência entre os conceitos, essa probabilidade deveria ficar em torno de 33\% (ou 1/3).

Figura 3 - Probabilidades condicionais entre os conceitos

Enade e IDD para os 10 cursos mais freqüentes - 2004-2006

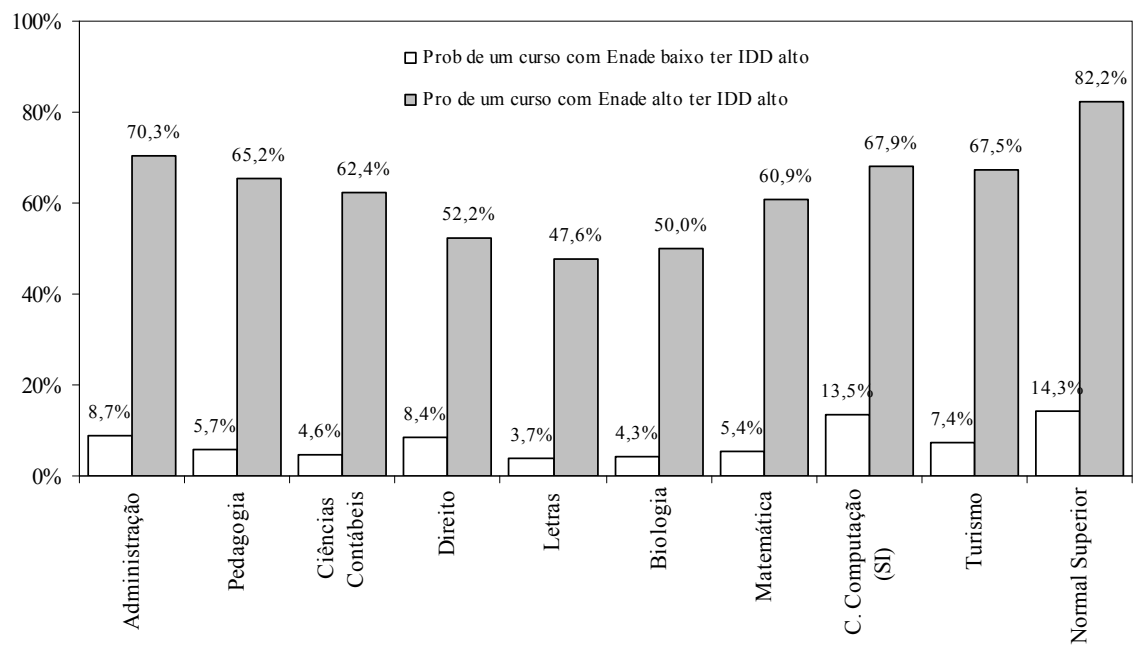

A razão entre as duas probabilidades varia entre 5 e 13, indicando que a probabilidade de um curso com conceito Enade alto apresentar um IDD igualmente alto é $400 \%$ a $1.200 \%$ vezes maior do que em cursos com Enade baixo.

Tabela 8 - Média da Formação Geral (FG) e Componente Específico (CE) dos ingressantes em função dos conceitos Enade e IDD

\begin{tabular}{cccccc}
\hline & Nível & \multicolumn{2}{c}{ FG Ingressantes } & \multicolumn{2}{c}{ CE Ingressantes } \\
\cline { 3 - 6 } & 1 & Média & $\begin{array}{c}\text { Desvio- } \\
\text { padrão }\end{array}$ & Média & $\begin{array}{c}\text { Desvio- } \\
\text { padrão }\end{array}$ \\
\hline \multirow{4}{*}{ IDD } & 47,37 & 10,93 & 30,36 & 8,13 \\
& 2 & 47,12 & 10,02 & 29,53 & 8,01 \\
& 3 & 46,95 & 9,73 & 29,64 & 8,20 \\
& 4 & 46,83 & 10,13 & 30,40 & 8,75 \\
& 5 & 46,13 & 10,80 & 29,89 & 8,89 \\
& Total & 46,94 & 10,04 & 29,84 & 8,33 \\
\hline \multirow{4}{*}{ Enade } & 1 & 28,32 & 17,63 & 17,32 & 10,46 \\
& 2 & 42,07 & 8,43 & 26,10 & 6,51 \\
& 3 & 46,59 & 9,35 & 28,99 & 7,47 \\
& 4 & 49,95 & 10,78 & 32,64 & 9,16 \\
& 5 & 57,77 & 9,03 & 38,47 & 10,85 \\
& Total & 46,66 & 10,91 & 29,51 & 8,82 \\
\hline
\end{tabular}


Buscando verificar se o IDD foi bem-sucedido na eliminação do efeito das desigualdades dos ingressantes na sua formulação, elaborou-se a tabela 8. Os resultados mostram que, tanto na FG como no $\mathrm{CE}$, as notas médias dos ingressantes praticamente não variam entre os cinco níveis do IDD, sugerindo que este indicador está cumprindo satisfatoriamente o seu papel. As mesmas médias, quando calculadas em função do conceito Enade revelam que, à medida que aumenta o conceito, aumenta também a média dos ingressantes, como era esperado.

\subsection{Resultados por Unidades da Federaçáo (UF)}

Com a finalidade adicional de avaliar a relação entre os conceitos, foram calculadas as médias dos indicadores Enade e IDD por Unidade da Federação (UF). Embora eles consistam de variáveis qualitativas ordinais e, portanto, não sejam passíveis da operação média, julgou-se pertinente proceder ao cálculo da média visto que ela é a única medida de tendência central capaz de considerar toda a informação disponível dentro de cada UF.

A figura 4 apresenta a relaçáo entre os conceitos Enade e IDD médios por Unidade da Federação (UF) e regióes. Quanto mais posicionados no canto superior direito do

Figura 4 - Relação entre os conceitos Enade e IDD médios por Estados e Regiões - 2004-2006

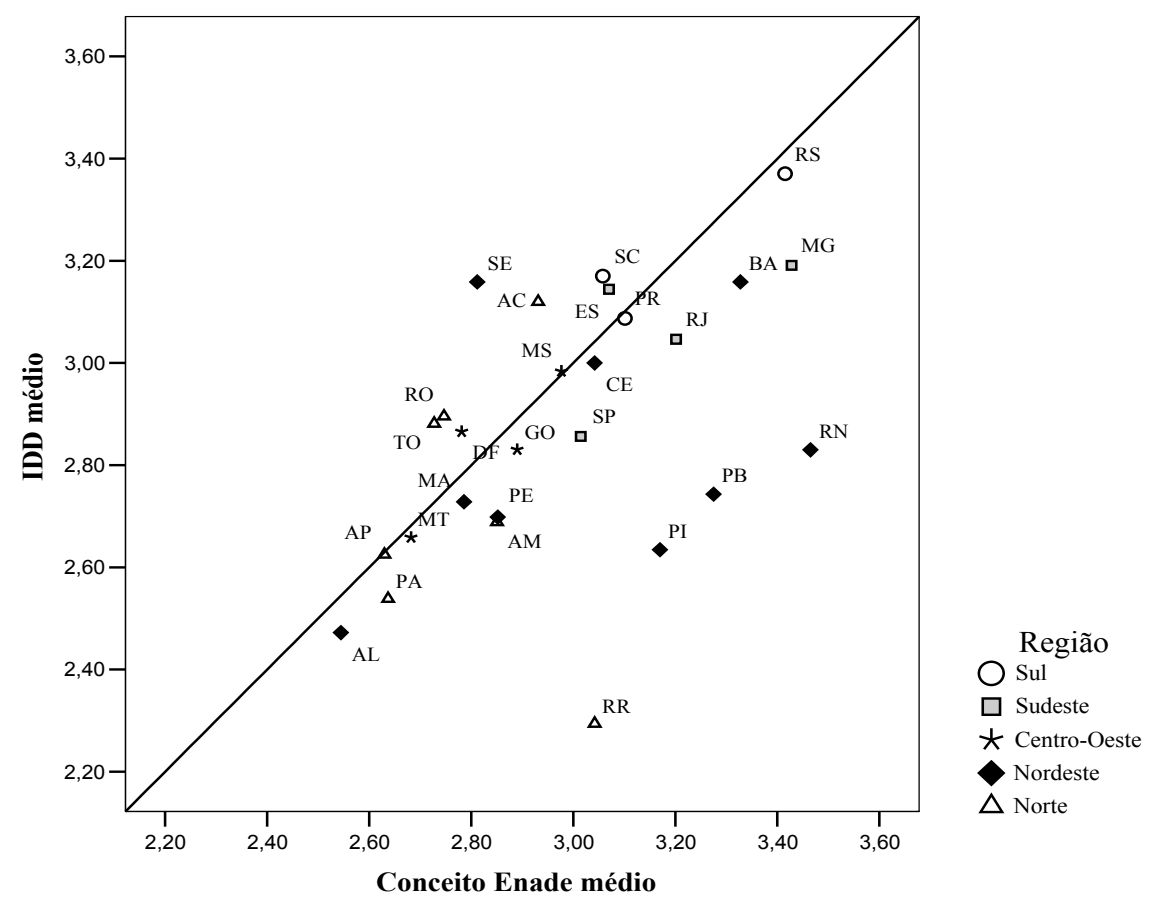


gráfico, melhores são os resultados, tanto no Enade quanto no IDD. De modo contrário, os desempenhos mais fracos estáo situados no canto inferior esquerdo.

Uma análise do diagrama permite identificar que o desempenho por região não é inteiramente homogêneo. Assim, as duas regióes que se destacam, por apresentarem Estados com os melhores desempenhos, são a Sul e a Sudeste, com o Estado do Rio Grande do Sul em melhor situação, seguido por Minas Gerais. A região Nordeste aparece em terceiro lugar com a Bahia, mas, por outro lado, apresenta também o desempenho geral mais fraco, como é o caso de Alagoas. O Rio Grande do Norte tem a maior média no Enade, entretanto no IDD apresenta desempenho mediano.

O gráfico de dispersão reforça a existência de uma associação direta entre os dois conceitos, revelando que, de modo geral, uma UF que apresenta média mais elevada do Enade tende, igualmente, a apresentar IDD médio mais alto.

\section{CONSIDERAÇÕES FINAIS}

Ainda que os índices Enade e IDD consistam de propostas distintas, seus resultados apresentam leve associação direta. Os dados revelam que é impossível prever, de maneira acurada, um dos conceitos tendo por base o conhecimento do outro. Por outro lado, pode-se afirmar que, de maneira geral, a probabilidade de se obter um IDD alto na presença de um conceito Enade alto (4 ou 5) mostrou-se aproximadamente cinco vezes maior do que para um Enade baixo (1 ou 2).

A definição de ambos os conceitos dá-se em uma espécie de competição entre as IES, na qual o desempenho de cada uma interfere na totalidade do processo de atribuição de notas e conceitos. O Enade pode ser considerado uma "competição" onde todos os cursos, independentemente das condiçóes iniciais, são avaliados de igual maneira, em uma versão modificada do procedimento adotado pelo Provão. O conceito IDD, por sua vez, apresentou um método de avaliação inovador, visando a equalizar a competição ao atribuir uma vantagem competitiva àqueles cursos com condiçôes iniciais desfavoráveis, tendo sido bem-sucedido no seu intento.

Ainda que a criaçáo do IDD tenha sido um dos pontos destacados como positivos do ENADE, há muitas ressalvas, por parte das IES, com relação à divulgação dos resultados na mídia. Como o Inep divulga os dois conceitos simultaneamente, as IES têm utilizado os que mais lhes convêm, identificando-se uma preferência pelo conceito Enade, o que provavelmente pode ser ocasionado pela sua semelhança metodológica com o Provão. A metodologia mais complexa do IDD pode estar refletindo negativamente na sua menor divulgação. 


\section{REFERÊNCIAS BIBLIOGRÁFICAS}

BRASIL. Exame Nacional de Cursos - Enade 2005. Resumo Técnico. Brasília, DF: MEC/ Inep, 2006.

COHEN, Jacob. A coefficient of agreement for nominal scales. Educational Psychology. n. 20, p. 27-46, 1960.

DIAS, C. L.; HORIGUELA, M. L. M.; MARCHELLI, P. S. Políticas para a avaliação da qualidade do ensino superior no Brasil: um balanço crítico. Educação e Pesquisa, v. 32, n.3, p. 435-64, 2006.

EVERITT, Brian. Analysis of contingency tables. London: Chapman and Hall, 1992, 168p.

GOUVEIA, A. B. et al. Trajetória da avaliação da Educação Superior no Brasil: singularidades e contradições (1983-2004). Estudos em Avaliação Educacional, v. 16, n. 31, p. 101-131, 2005.

LANDIS, J. R.; KOCH, G. G. The Measurement of observer agreement for categorical data. Biometrics, n. 33, p.159-174, 1977.

POLIDORI, M. M.; MARINHO-ARAÚJO, C. M.; BARREYRO, G. B. Sinaes: perspectivas e desafios na avaliação da educação superior brasileira. Ensaio: Avaliação e Políticas Públicas em Educação, v. 14, n. 53, p. 425-436, 2006. RISTOFF, D.; GIOLO, J. O Sinaes como sistema. $R$ $B P G$, v. 3, n. 6, p. 193-213, 2006.

VERHINE, R. E.; DANTAS, L. M. V.; SOARES, J. F. Do Provão ao Enade: uma análise comparativa dos exames nacionais utilizados no Ensino Superior brasileiro. Ensaio: Avaliação e Políticas Públicas em Educação, v. 14, n. 52, p. 291-310, 2006.

VIALI, L.; BITTENCOURT, H. R. Propostas para mensurar o grau de não-casualidade em avaliações objetivas. Estudos em Avaliação Educacional, v.18, n.36, p.97-114, jan./abr. 2007. VIANNA, H. M. Avaliações Nacionais em Larga Escala: análises e propostas. São Paulo: FCC/ DPE: 2003, 41p. (Textos FCC, n. 23)

Recebido em: maio 2008

Aprovado para publicação em: junho 2008

Hélio Radke Bittencourt é Professor da Faculdade de Matemática da Pontifícia Universidade Católica do Rio Grande do Sul (heliorb@pucrs.br); Lorí Viali é Professor da Faculdade de Matemática da Pontifícia Universidade Católica do Rio Grande do Sul e Universidade Federal do Rio Grande do Sul (viali@pucrs.br); Alam de Oliveira Casartelli é Professor da Faculdade de Administração, Contabilidade e Economia da Pontifícia Universidade Católica do Rio Grande do Sul (alam@pucrs.br); Alziro Cesar de M. Rodrigues é Professor da Faculdade de Administração, Contabilidade e Economia da Pontifícia Universidade Católica do Rio Grande doSul (rodrigues@pucrs.br). 